\title{
WATER QUALITY EVALUATION AND TREND ANALYSIS OF HUNHE RIVER BASIN IN THE UPSTREAM OF DAHUOFANG RESERVOIR
}

\author{
YAN, B. ${ }^{*}$ - LIU, Y. T. - WANG, T. L. - JIANG, X. H. \\ Shenyang Agricultural University, No. 120, Dongling Road, Shenhe District, Shenyang 110866, \\ Liaoning Province, China \\ *Corresponding author \\ e-mail: 1993500019@syau.edu.cn; phone: +86-158-0246-3828; fax: +86-024-8848-7134 \\ (Received 22 ${ }^{\text {nd }}$ Apr 2019; accepted $12^{\text {th }}$ Jul 2019)
}

\begin{abstract}
Dahuofang Reservoir is an important drinking water source. Hunhe, Suzihe and Shehe are three main input rivers, the water quality of which directly affects the water safety. Traditional water quality analysis often adopts a single analysis method, which can only judge the rising or falling trend and trend degree of a certain parameter. The calculation process of multi-section and multi-index trend analysis is quite complicated with a large workload. Thus, in this paper, Nemerow index evaluation method was used to evaluate the water quality, 24 indicators being screened to 8 , greatly reducing calculating workload. Then, trend analysis was made by seasonal Kendall test method. The results show that the Nemerow indices of TN in the three river sections were 6.94, 6.68 and 6.30, exceeding $38.8 \%, 33.6 \%$ and $26 \%$ of serious pollution standard (5.0) respectively, and with a highly significant upward trend. Those of fecal coliform were $17.42,3.12$ and 2.79 respectively. Beizamu section was seriously polluted, exceeding $248.4 \%$ of serious pollution standard (5.0). Gulou section belonged to heavy pollution, exceeding $4 \%$ of standard (3.0). Taigou section was also polluted, exceeding $39.5 \%$ of standard (2.0). Therefore, effective measures should be taken to control TN and fecal coliform concentrations in the three sections.
\end{abstract}

Keywords: water pollution, indicator screening, Nemerow index evaluation, seasonal Kendall test

\section{Introduction}

According to the Chinese Water Resources Bulletin 2017, the per capita water resource amounts to only $2300 \mathrm{~m}^{3}$ in China, only a quarter of the world average, belonging to water shortage country. With the development of industry, acceleration of urbanization and the expansion of population, China face with a very severe environmental situation. Class I to III water quality section of the main watershed of the country accounts for $67 \%$, while inferior $\mathrm{V}$ accounts for $12.9 \%$. Among which, the Haihe River Basin is a serious pollution, and the Yellow River, Huaihe and Liaohe Basins are moderately polluted (Ministry of Water Resources, 2017).

In the 1960s, under rapid industrial development, China ignored the protection of the ecological environment, causing different levels of environmental pollution and ecological damage, resulting in frequent occurrence of water pollution accidents. The obvious increasing trend of water pollution accidents is a direct threat to the security of drinking water supply. Water pollution has become a major obstacle on the road of sustainable development in China. In the $19^{\text {th }}$ National Congress of CPC, it was clearly pointed out that we should strengthen the construction of water resources and other infrastructure, adhere to the construction of ecological civilization, create a good living environment for the people, and contribute to the global ecological security. River water quality assessment is the most important basic work in the process of water environment management and improvement. Therefore, the evaluation of river water quality and the 
analysis of the trend of water quality are of great significance to the control of water environmental pollution, the construction of ecological civilization and the guarantee of ecological security.

At present, the commonly used water quality evaluation methods include single factor evaluation method, index evaluation method, fuzzy evaluation method, artificial neural network evaluation method, grey clustering method and so on. The single factor evaluation method is to evaluate each water quality monitoring indicators in the water separately, and determine the comprehensive water quality level in the measured area according to the level of the worst individual water quality indicators. The evaluation method is simple to operate (Yin, 2008). The index evaluation method is generally divided into Nemerow index method, comprehensive pollution index evaluation method, water pollution index method and so on (Liu, 2010). The index evaluation method selects the indexes and evaluation criteria according to the use of water, so as to obtain the index value of a single water quality indicator. If a comprehensive evaluation is required, the weight of each indicator needs to be determined to calculate the water quality index, and the water quality evaluation is performed (Liu, 2016). The fuzzy evaluation method is to convert the qualitative analysis into quantitative calculation by the membership degree theory of fuzzy mathematics, and evaluate the water quality grade. This method combines different weight determination methods to avoid the subjectivity of the selection of weight coefficients, making the evaluation results more reasonable, but the calculation process is more complicated (Pan, 2002). Artificial neural network is a complex nonlinear science. It is introduced into the field of water quality assessment, which can fully utilize the high-speed computing power, learning ability and fault tolerance of neural networks, improve the accuracy of water quality evaluation, and avoid human factors in weight selection. However, this method requires a large amount of complete data, and the more complete the data, the higher the accuracy. The gray clustering method is based on the whitening function possessed by the clustering index of different clusters, and the clustering objects are summarized to find the maximum clustering coefficient. The clustering sample level is the water quality level. This method is used for clustering weighting by judging the grey, whitening degree of the system and the comprehensive influence of various pollution indicators, to make the weight determination method more reasonable (Yuan, 2003).

Huang (2013) and Ma (2014) evaluated the water quality of Dahuofang Reservoir in Liaoning Province by using fuzzy evaluation method and BP neural network method respectively, and drew the conclusion that the water quality in the reservoir area was class II level, while in Hunhe River and Suzihe River were all class III level and there was a certain eutrophication risk. It is mainly caused by livestock and poultry breeding, fertilizer use and sewage discharge. Zhou (2015) used the grey clustering evaluation method based on index transformation value to evaluate the water quality of the study area, which overcomes the shortcomings of randomness, ambiguity and uncertainty due to multi-index coupling in the calculation process. After verification, the results are reasonable and accurate. But in the verification process, this method only focuses on the water quality of the study area. Whether it can be popularized or applied remains to be verified. Luo and $\mathrm{Wu}$ (2016) put forward the improved Nemerow index evaluation method, in addition to considering the weight of each pollution index; we also pay special attention to the monitoring factors with higher weight to make comprehensive evaluation of water quality. The Nemerow index method has a simple mathematical process and is easy to calculate. It can be used to understand whether the water quality 
meets the requirements. Therefore, the Nemerow index method is widely used in water quality evaluation. However, there are still some shortcomings in the classification of water quality, such as being affected by human factors, and no strict corresponding relationship between this division standard and the national standard level. Guan (2017) proposed pollution index method based on the CRITIC weight, and built a water quality evaluation model. Using CRITIC method to determine the weight takes into account the difference and conflict between the indicators on the weight, is an improvement of the entropy weight method, can objectively determine the weight value. This method overcomes the one-sided problem of single factor evaluation, and the calculation process of weight determination is relatively simple. But the method is more dependent on water quality monitoring results.

For water quality trend analysis, the commonly used statistical test methods include seasonal Kendall test, Daniel test, Spearman rank correlation coefficient method, etc. (Gao, 2013). The seasonal Kendall test is a generalization of the Mann-Kendall test (Mann, 1945; Kendall, 1975). In recent years, its calculation process has been gradually improved and applied to the trend analysis of water quality of major rivers. The results are scientific and reasonable. Although this method can determine the rise and fall tendency and trend degree of water quality parameters, it cannot reflect the result of water quality evaluation. Meng (2015) used the seasonal Kendall test to analyze the trend of water quality in the main stream of Minjiang River, pointed out the change trend of the four indicators of chemical oxygen demand (COD), five days biochemical oxygen demand ( $\left.\mathrm{BOD}_{5}\right)$, total phosphorus (TP) and ammonia nitrogen, analyzed the reasons, and proposed corresponding treatment measures. However, the reasons for selecting these four indicators for analysis were not explained. Pang (2017) analyzed the variation trend of groundwater quality in Guanghua Basin using the Spearman rank correlation coefficient method. This method is relatively mature at present, but it can only judge the variation trend from the past to the present and cannot represent the real change of the pollution factor in the future period. Guo (2017) used Daniel test method to analyze the trend of water quality of Nanhai reservoir in Zhangwu. The rank correlation coefficient for statistical tests was compared with Spearman rank correlation coefficient to analyze the variation trend. However, this method requires sufficient available data, while the seasonal Kendall test is not affected by missing measured values. At present, for the study of water quality analysis, people often only pay attention to unilateral water quality evaluation or trend analysis, ignoring the shortcomings of the multi-section and multi-index trend analysis process. Therefore, in this paper we combined water quality evaluation with seasonal Kendall test method. According to the evaluation results, the indexes to be evaluated were selected, which greatly reduced the calculation amount, made up for the deficiency that seasonal Kendall test cannot reflect the evaluation results, and reflected the changing trend of river water quality more intuitively.

\section{Materials and methods}

\section{Materials}

Dahuofang Reservoir is an important drinking water source of Shenyang, Fushun, Anshan, Liaoyang and some other central cities. It belongs to zonal-valley-type reservoir, about $35 \mathrm{~km}$ long in west-east direction, $4 \mathrm{~km}$ wide at its widest point, and $0.3 \mathrm{~km}$ wide at its narrowest point at the water surface. The project is a large-type 
reservoir with a maximum depth of $37 \mathrm{~m}$, maximum water storage area of $114 \mathrm{~km}^{2}$, and a maximum storage capacity of $2.268 \times 10^{9} \mathrm{~m}^{3}$. The annual average water evaporation in the basin is about 1100 1600 mm (according to the $20 \mathrm{~cm}$ scale evaporative dish). The average annual inflow is about $789.36 \mathrm{~m}^{3} / \mathrm{s}$, and its wet season is from April to September. The basin above Dahuofang Reservoir belongs to Hunhe River Basin, Suzihe River Basin and Shehe River Basin, and belongs to the mixed area of agriculture and forestry. In Hunhe River Basin, there are $3.45 \times 10^{5}$ population in Qingyuan County and $3.94 \times 10^{4} \mathrm{hm}^{2}$ cultivated area. The domestic sewage reaches $1.74 \times 10^{4} \mathrm{t} / \mathrm{d}$, due to the existence of chemical mines such as Qingyuan Limestone Mine, lead to the industrial sewage reaches $1.32 \times 10^{4} \mathrm{t} / \mathrm{d}$, and the total amount of sewage in the county is $3.06 \times 10^{4} \mathrm{t} / \mathrm{d}$. The annual application amount of chemical fertilizer in Qingyuan County is $1.8 \times 10^{4} \mathrm{t}$, pesticide application amount is $280 \mathrm{t}$, and the dosage of film is $200 \mathrm{t}$, which caused the loss of most of the chemical substances and thus polluted the water environment. In Suzihe River Basin, there are $3.08 \times 10^{5}$ population in Xinbin County and $5.10 \times 10^{4} \mathrm{hm}^{2}$ cultivated area. The sewage can be basically treated by a sewage treatment plant. The domestic sewage treatment capacity reaches $1.61 \times 10^{4} \mathrm{t} / \mathrm{d}$. In this basin, the pesticide application amount is $2.55 \mathrm{~kg} / \mathrm{hm}^{2}$, lower than the national standard. In Shehe River Basin, there are $3.83 \times 10^{4}$ population and $4.78 \times 10^{3} \mathrm{hm}^{2}$ cultivated area. It is a river with the best water quality in the upstream rivers since there is no largescale enterprise. The three rivers upstream of Dahuofang Reservoir are the main water sources of the reservoir, with Hunhe River accounting for $52.7 \%$ of the water storage, Suzihe River accounting for $37.1 \%$, and Shehe River accounting for $10.2 \%$ (Dahuofang Reservoir Chronicles, 2006). The location map of Dahuofang Reservoir and upstream watershed is shown in Figure 1.

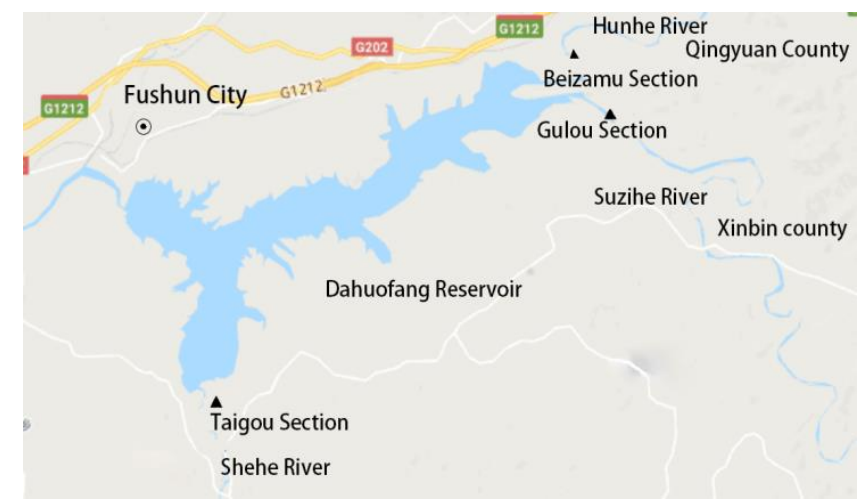

Figure 1. Location map of Dahuofang Reservoir and upstream watershed

In this study, the Beizamu section on Hunhe River, the Gulou section on Suzihe River and the Taigou section on Shehe River were taken as the main monitoring sections on the three input rivers upstream of Dahuofang Reservoir. The water quality monitoring data from 2003 to 2015 were analyzed. The original data were obtained from the monthly average water quality monitoring data of the three monitoring sections from April 23, 2003 to December 7, 2015 provided by the Fushun Hydrology Bureau of Liaoning Province.

The water quality of the three sections ranged from good to bad: Taigou section > Gulou section > Beizamu section. In 2015, there are six indicators that exceed the standard of the national surface water class II in Beizamu section: total nitrogen 
(TN) $100 \%$, fecal coliform count 100\%, dissolved oxygen (DO) $23.3 \%$, ammonia nitrogen $22 \%$, five-day biochemical oxygen demand (BOD 5 ) $16.7 \%$, total phosphorus (TP) $10 \%$. There are two indicators that surpass the standard of the national surface water class II in Gulou section: total nitrogen (TN) 100\%, fecal coliform count 5\%. There are two indicators that exceed the standard of the national surface water class II in the Taigou section: total nitrogen (TN) 100\%, dissolved oxygen (DO) 1.7\%. The National Surface Water Quality (NSWQ) classification standards (Ministry of Environmental Protection, 2002) are presented in Table 1.

Table 1. Chinese national surface water quality classification standards (GB3838-2002)

\begin{tabular}{|c|c|c|c|c|c|}
\hline \multirow{2}{*}{ Indicators } & \multicolumn{5}{|c|}{ Classification } \\
\hline & I & II & III & IV & $\mathbf{V}$ \\
\hline $\mathrm{DO} \geq\left(\mathrm{mgL}^{-1}\right)$ & 7.5 & 6 & 5 & 3 & 2 \\
\hline Permanganate $\leq\left(\mathrm{mgL}^{-1}\right)$ & 2 & 4 & 6 & 10 & 15 \\
\hline $\mathrm{BOD}_{5} \leq\left(\mathrm{mgL}^{-1}\right)$ & 3 & 3 & 4 & 6 & 10 \\
\hline $\mathrm{COD} \leq\left(\mathrm{mgL}^{-1}\right)$ & 15 & 15 & 20 & 30 & 40 \\
\hline Ammonia Nitrogen $\leq\left(\mathrm{mgL}^{-1}\right)$ & 0.15 & 0.5 & 1.0 & 1.5 & 2.0 \\
\hline $\mathrm{TN} \leq\left(\mathrm{mgL}^{-1}\right)$ & 0.2 & 0.5 & 1.0 & 1.5 & 2.0 \\
\hline $\mathrm{TP} \leq\left(\mathrm{mgL}^{-1}\right)$ & 0.02 & 0.1 & 0.2 & 0.3 & 0.4 \\
\hline Fecal Coliform Count $\leq\left(10^{-1} \mathrm{mpn} 100 \mathrm{~mL}^{-1}\right)$ & 200 & 2000 & 10,000 & 20,000 & 40,000 \\
\hline
\end{tabular}

\section{Methods}

In the study of water quality trend analysis, people often use only a certain trend analysis method to analyze the water quality of a river, and then get the trend of water quality change. However, in this paper, the trend of water quality in 3 sections of three rivers in the upstream of Dahuofang Reservoir will be analyzed. There are 8 indicators to be evaluated for each section, altogether 24 indexes. If the seasonal Kendall test method is used alone, the calculation amount will be large. The Nemerow index method is simple in calculation and widely used in water quality assessment. Therefore, the Nemerow index evaluation method was used to evaluate the water quality. According to the evaluation results, the polluted indicators were screened out. The seasonal Kendall test was applied to the selected indicators, which reduced the amount of calculation and made up for the shortcomings of seasonal Kendall test method which can not reflect the evaluation results. Thus, the trend analysis results were obtained, which was also the innovation of this paper.

\section{Nemerow index evaluation method}

The Nemerow index evaluation method is based on the single factor index evaluation method to evaluate water quality. The single factor index evaluation method is a method to determine the water quality category by comparing the measured concentration of a certain pollution index with the evaluation standard of the pollution index. Each water quality monitoring indicator is evaluated separately, and the category of the worst single water quality index is selected to determine the comprehensive water quality category of the measured area. The main pollution factors in river water could be determined by single factor index evaluation. The evaluation index $\mathrm{F}_{i}$ is calculated as follows: 
(1) For the water quality factors whose evaluation criteria are constant values, the evaluation index is calculated by Equation 1.

$$
F_{i}=\frac{C_{i}}{C_{0}}
$$

where $\mathrm{F}_{i}$ is the evaluation index of monitoring indicator $i$ in river water, $\mathrm{C}_{i}$ is the measured concentration of indicator $i\left(\mathrm{mg} \mathrm{L}^{-1}\right)$, and $\mathrm{C}_{0}$ is the evaluation criteria of indicator $i$.

(2) For the water quality factors whose evaluation standards are interval values (such as $\mathrm{PH}$ value), the evaluation index is calculated by Equations 2 and 3.

$$
\begin{gathered}
P_{p H}=\frac{7.0-p H}{7.0-p H_{s d}} \text { If } p H \leq 7.0 \\
P_{p H}=\frac{p H-7.0}{p H_{s u}-7.0} \text { If } p H \geq 7.0
\end{gathered}
$$

Herein, $\mathrm{P}_{p H}$ is the evaluation index of $\mathrm{pH}$, dimensionless; $\mathrm{pH}$ is the measured value; $\mathrm{pH}_{s d}$ is the lower limit value of the standard; $\mathrm{pH}_{s u}$ is the upper limit value of the standard.

When Fi is less than 1, it means the river water body is not polluted. When $\mathrm{F}_{i}$ is greater than 1, it means the river water body has been polluted. The greater the $\mathrm{F}_{i}$ is, the more serious the pollution is (Luo and Zhang, 2016). In particular, the situation of dissolved oxygen (DO) is just the opposite.

For Nemerow index method, firstly, a series of $\mathrm{F} i$ values of indicators were calculated by single-factor evaluation method based on the ratio of measured concentration and standard value of selected water quality indicators; then Nemerow pollution index was obtained according to the maximum and average value of $\mathrm{F} i$. Compared with the corresponding grade standard index (Luo and $\mathrm{Wu}, 2016$ ), the evaluation grade can be determined to judge the pollution situation. The calculation method is shown in Equation 4.

$$
P=\left[\frac{\left(F_{\max }\right)^{2}+(\bar{F})^{2}}{2}\right]^{1 / 2} \bar{F}=\frac{1}{n} \sum_{i=1}^{n} F_{i}
$$

where $P$ is the Nemerow index of river water quality monitoring indicators; $F_{\max }$ is the maximum $F_{i}$ value of indicator $i$; and $\bar{F}$ is the average of $F_{i}$ of indicator $i$. Particularly, for DO concentration index, the $F_{\max }$ in the formula should be changed to $F_{\min }$, that is, the minimum $F_{i}$ value of indicator $i$.

It can be seen that Nemerow index is a comprehensive evaluation of river water quality based on the single-factor index method, which is different from the traditional single-factor index method. On the premise of judging pollution according to the 
NSWQ, the possible pollution indicators are evaluated, so that the number of water pollution indicators can be effectively deleted to reduce the calculation workload of the seasonal Kendall test.

\section{Seasonal Kendall test}

The seasonal Kendall test is a method based on the Mann-Kendall test, which is used to analyze the variation trend of water quality over the years with incomplete measured water quality data, low accuracy of data or regularly changing values with seasons (Onoz, 2003). The test statistic (S) is calculated by Equations 5 and 6.

$$
\begin{gathered}
\operatorname{sgn}\left(x_{j}-x_{i}\right)= \begin{cases}1 & x_{j}-x_{i}>0 \\
0 & x_{j}-x_{i}=0 \\
-1 & x_{j}-x_{i}<0\end{cases} \\
S_{p}=\sum_{i=1}^{n-1} \sum_{j=i+1}^{n} \operatorname{sgn}\left(x_{j}-x_{i}\right)
\end{gathered}
$$

Herein, $x_{i}$ and $x_{j}$ are the measured values of pollutant concentration in month $p$ each year; $S_{p}$ is the $S$ value in month $p, p=1,2, \ldots 12$.

The null hypothesis $H_{0}$ of seasonal Kendall test is a random variable, independent of each other in time. Assuming that the water quality data over 12 months have the same probability distribution, $S_{\mathrm{p}}$ approximately obeys the normal distribution under zero assumption. The expression of its mean and variance are shown in Equations 7 and 8.

$$
\begin{gathered}
\mathrm{E}\left(\mathrm{S}_{\mathrm{p}}\right)=0 \\
\operatorname{Var}\left(S_{p}\right)=\frac{n_{p}\left(n_{p}-1\right)\left(2 n_{p}+5\right)-t_{p}\left(t_{p}-1\right)\left(2 t_{p}+5\right)}{18}
\end{gathered}
$$

where $n_{\mathrm{p}}$ and $t_{\mathrm{p}}$ are the number of measured values and missed values at month $p$, respectively.

For the whole $p$ months, $S=\sum_{p=1}^{12} S_{p}, \operatorname{Var}(S)=\sum_{p=1}^{12} \operatorname{Var}\left(S_{p}\right)$. If $n$ is no less than 10 , and $S$ satisfies the normal distribution feature, then its standardized variance $Z$ is described as Equation 9.

$$
Z=\left\{\begin{array}{c}
\frac{S-1}{[\operatorname{Var}(S)]^{1 / 2}}, S>0 \\
0, S=0 \\
\frac{S+1}{[\operatorname{Var}(S)]^{1 / 2}}, S<0
\end{array}\right.
$$


The calculated $Z$ value is compared with the standard normal distribution table with two-sided confidence levels. If $|Z| \leq Z_{\alpha / 2}$ at the $\alpha$ level of significance, $H_{0}$ should be accepted. According to the relevant research results (Robert, 1984), the critical value of significance level $\alpha$ is 0.1 and 0.01. If $\alpha \leq 0.01,|Z| \geq Z_{\alpha / 2}$, the test is highly significant; if $0.01 \leq \alpha \leq 0.1,|Z| \geq Z_{\alpha / 2}$, the test is significant. If $S>0$, it shows a significant upward trend; if $S<0$, it shows a significant downward trend; if $S=0$, there is no obvious variation trend.

\section{Results}

\section{Results of Nemerow index evaluation}

The data of the main monitoring sections of three rivers in the upstream of Dahuofang Reservoir from 2003 to 2015 were analyzed. Compared with the NSWQ (GB3838-2002), according to the grade II water quality standard, 8 major pollution indicators per section were screened out, which were $\mathrm{DO}$, permanganate index, $\mathrm{BOD}_{5}$, Chemical oxygen demand (COD), ammonia nitrogen, TN, TP and fecal coliform. Therefore, there are 24 indicators to be evaluated for the three monitoring sections. According to the measured concentration of each indicator, the $F_{i}$ value of the corresponding year was obtained, and its average value and maximum value was calculated, thus the Nemerow pollution index was obtained. The results are shown in Table 2.

Table 2. Nemerow pollution index

\begin{tabular}{c|c|c|c|c|c|c|c|c|c}
\hline \multirow{2}{*}{ Indicators } & \multicolumn{3}{|c|}{ Beizamu section } & \multicolumn{3}{c|}{ Gulou section } & \multicolumn{3}{c}{ Taigou section } \\
\cline { 2 - 10 } & $\bar{F}$ & $\boldsymbol{F}_{\boldsymbol{m a x}}$ & $\boldsymbol{P}$ & $\bar{F}$ & $\boldsymbol{F}_{\boldsymbol{m a x}}$ & $\boldsymbol{P}$ & $\bar{F}$ & $\boldsymbol{F}_{\boldsymbol{m a x}}$ & $\boldsymbol{P}$ \\
\hline DO & 1.53 & 1.72 & 1.63 & 1.60 & 1.88 & 1.75 & 1.59 & 1.87 & 1.73 \\
Permanganate & 0.86 & 1.31 & 1.11 & 0.65 & 1.05 & 0.87 & 0.53 & 0.82 & 0.69 \\
BOD $_{5}$ & 0.60 & 1.05 & 0.86 & 0.47 & 0.69 & 0.59 & 0.39 & 0.51 & 0.45 \\
COD & 0.84 & 0.93 & 0.89 & 0.77 & 0.94 & 0.86 & 0.72 & 0.82 & 0.77 \\
Ammonia nitrogen & 0.76 & 1.34 & 1.09 & 0.47 & 1.28 & 0.96 & 0.41 & 0.85 & 0.67 \\
TN & 6.05 & 7.73 & 6.94 & 5.25 & 7.85 & 6.68 & 5.17 & 7.27 & 6.30 \\
TP & 0.44 & 0.98 & 0.76 & 0.35 & 0.93 & 0.70 & 0.29 & 0.55 & 0.44 \\
Fecal coliform & 5.89 & 23.93 & 17.42 & 1.62 & 4.11 & 3.12 & 1.40 & 3.69 & 2.79 \\
\hline
\end{tabular}

If the $P$ value of DO is greater than 1 , it is indicated that dissolved oxygen is a clean index. By comparing with the classification criteria for pollution grade of Nemerow water quality index (see Table 3), the clean indicators were excluded, the indicators belonging to different degrees of pollution were retained, and the pollution indicators of the three sections was reduced from 24 to 8 (see Table 4).

Table 3. Classification criteria for pollution grade of Nemerow water quality index

\begin{tabular}{c|c|c|c|c|c}
\hline $\mathbf{P}$ & $<\mathbf{1}$ & $\mathbf{1 - 2}$ & $\mathbf{2 - 3}$ & $\mathbf{3 - 5}$ & $>\mathbf{5}$ \\
\hline Water quality level & Clean & Light pollution & Pollution & Heavy pollution & Serious pollution \\
\hline
\end{tabular}


Table 4. Screened indicators and pollution levels

\begin{tabular}{c|c|c|c}
\hline Sections & Indicators & P Value & Pollution Level \\
\hline \multirow{3}{*}{ Beizamu } & Permanganate & 1.11 & Light pollution \\
& Ammonia nitrogen & 1.09 & Light pollution \\
& TN & 6.94 & Serious pollution \\
& Fecal coliform & 17.42 & Serious pollution \\
\hline \multirow{2}{*}{ Gulou } & TN & 6.68 & Serious pollution \\
& Fecal coliform & 3.12 & Heavy pollution \\
\hline \multirow{2}{*}{ Taigou } & TN & 6.30 & Serious pollution \\
& Fecal coliform & 2.79 & Pollution \\
\hline
\end{tabular}

It is obvious that:

(1) In Beizamu section, the Nemerow indexes of TN and fecal coliform were 6.94 and 17.42, respectively, which belonged to serious pollution. The Nemerow indexes of permanganate index and ammonia nitrogen were 1.11 and 1.09 , respectively, which belonged to light pollution. Other indicators were all clean indicators;

(2) In Gulou section, the Nemerow index of TN was 6.68, which belonged to serious pollution. The Nemerow index of fecal coliform was 3.12, which was a heavy pollution. Others were all clean indicators;

(3) In Taigou section, the Nemerow index of TN was 6.30, which was a serious pollution. The Nemerow index of fecal coliform was 2.79 , belonging to pollution. Others were all clean indicators.

In order to further verify the variation trend of the above pollution indicators, the seasonal Kendall test was conducted on the selected 8 indicators.

\section{Results of seasonal Kendall test}

According to the evaluation results of Nemerow index method, seasonal Kendall test was performed on the following indicators: permanganate index, ammonia nitrogen concentration, TN and fecal coliform in Beizamu section; TN and fecal coliformt in Gulou section; TN and fecal coliform in Taigou section. The test results are shown in Table 5.

The test results showed that $\mathrm{Z}$ values of TN in the three sections were 2.945, 4.951 and 5.133, respectively, with a highly significant upward trend, while the other indicators showed no significant variation trend.

\section{Discussion}

The above analysis results reveal that:

(1) TN and fecal coliform in Beizamu section belong to serious pollution, exceeding the pollution standards (the minimum standard index is 5.0 ) by $38.8 \%$ and $248.4 \%$, respectively. Permanganate index and ammonia nitrogen are light pollution, exceeding $31 \%$ and $34 \%$ of the minimum pollution standards (1.0), respectively. These four pollution indicators are consistent with the main pollution indicators determined by Huang (2013) using the fuzzy evaluation method. Firstly, the Hunhe River Basin where the Beizamu section is located has a large population $\left(3.45 \times 10^{5}\right.$ people), and a large amount of domestic sewage $\left(1.74 \times 10^{4} \mathrm{t} / \mathrm{d}\right)$, which leads to the excessive number of 
fecal coliform bacteria. Secondly, the upstream industrial mines (e. g. Qingyuan Limestone Mine) still exist, and the industrial wastewater discharge is large $\left(1.32 \times 10^{4} \mathrm{t} / \mathrm{d}\right)$ and the treatment is not timely, resulting in slight pollution of permanganate index and ammonia nitrogen. Pang (2017) also mentioned the reason why the ammonia nitrogen concentration exceeded the standard in the analysis of groundwater quality in Guanghua Basin. Thirdly, the cultivated land area of Hunhe River Basin is relatively large $\left(3.94 \times 10^{4} \mathrm{hm}^{2}\right)$. Due to the large use of pesticides and fertilizers, the TN exceeds the limit, which leads to the risk of eutrophication in water.

Table 5. Seasonal Kendall test results

\begin{tabular}{|c|c|c|c|c|c|c|c|}
\hline Sections & Indicators & $\mathbf{S}$ & VarS & $\mathbf{Z}$ & $\begin{array}{c}\alpha=\mathbf{0 . 1} \\
Z_{\alpha / 2}=1.645\end{array}$ & $\begin{array}{c}\alpha=\mathbf{0 . 0 1} \\
Z_{\alpha / 2}=2.576\end{array}$ & $\begin{array}{l}\text { Water } \\
\text { quality } \\
\text { trends }\end{array}$ \\
\hline \multirow{4}{*}{ Beizamu } & Permanganate & 28 & 1878.0 & 0.62 & $<$ & $<$ & No trend \\
\hline & Ammonia nitrogen & -61 & 1414.0 & -1.596 & $<$ & $<$ & No trend \\
\hline & $\mathrm{TN}$ & 114 & 1472.7 & 2.945 & $>$ & $>$ & $\begin{array}{l}\text { Highly } \\
\text { significant } \\
\text { increase }\end{array}$ \\
\hline & Fecal coliform & 43 & 1766.0 & 0.999 & $<$ & $<$ & No trend \\
\hline \multirow[t]{2}{*}{ Gulou } & $\mathrm{TN}$ & 191 & 1472.7 & 4.951 & $>$ & $>$ & $\begin{array}{l}\text { Highly } \\
\text { significant } \\
\text { increase }\end{array}$ \\
\hline & Fecal coliform & -69 & 1766.0 & -1.618 & $<$ & $<$ & No trend \\
\hline \multirow[t]{2}{*}{ Taigou } & TN & 198 & 1472.7 & 5.133 & $>$ & $>$ & $\begin{array}{l}\text { Highly } \\
\text { significant } \\
\text { increase }\end{array}$ \\
\hline & Fecal coliform & -41 & 1822.0 & -0.937 & $<$ & $<$ & No trend \\
\hline
\end{tabular}

(2) TN in Gulou section belongs to serious pollution, exceeding the pollution standard (the minimum standard index is 5.0) by 33.6\%. Fecal coliform belongs to heavy pollution, exceeding $4 \%$ of the minimum pollution standard (3.0). This is due to the fact that the Suzi River Basin, where the Gulou section is located, has a large population $\left(3.08 \times 10^{5}\right.$ people $)$ and a large amount of domestic sewage $\left(1.6 \times 10^{4} \mathrm{t} / \mathrm{d}\right)$. However, there are sewage treatment plants in the area, which can discharge domestic sewage after treatment. Therefore, the quantity of fecal coliform is significantly less than that of Beizamu section, but there is still a certain degree of pollution. The number of fecal coliforms in the Aibihu Lake Wetland Nature Reserve has also shown a significant downward trend after the establishment of sewage treatment plants and the treatment of domestic sewage to meet the discharge standards (Ren, 2011). In addition, the cultivated land area in the Suzi River Basin $\left(5.1 \times 10^{4} \mathrm{hm}^{2}\right)$ is larger than in the Hunhe River Basin, and the application of pesticides and fertilizers is more, resulting in serious pollution of $\mathrm{TN}$.

(3) TN in Taigou section belongs to serious pollution, exceeding the pollution standard (the minimum standard index is 5.0 ) by $26 \%$. Fecal coliform belongs to pollution, exceeding $39.5 \%$ of the minimum pollution standard (2.0). This is due to the population of Shehe River Basin where the Taigou section is located is small $\left(38,381\right.$ people), the cultivated land area is also small $\left(4776.5 \mathrm{hm}^{2}\right)$, and there is no 
large-scale industrial enterprise in the upstream. Therefore, compared with the Hunhe River Basin and the Suzi River Basin, the water quality is better. This conclusion is consistent with the research result of Shi (2004). However, because of the discharge of domestic sewage and the use of pesticides and fertilizers, the TN and fecal coliforms are still polluted to varying degrees.

(4) TN concentration in the three sections of Beizamu, Gulou, Taigou all show a highly significant upward trend, while the other indicators show no significant change trend. Fang (2017) analyzed the change trend of TN concentration in the Beizamu section of Hunhe River and drew the same conclusion. This change is associated with the large-scale application of chemical fertilizers in the upstream farmland. Among the fertilizers applied in the study area, the nitrogen content accounts for $49.5 \%$ of the total content (Tang, 2016). The large amount of chemical fertilizers has resulted in nitrogen residue in soil, and with the surface runoff flowing into rivers. The TN concentration has a highly significant upward trend due to the long-term excess of nitrogen. The interannual variation curves of the TN concentration in the three sections from 2003 to 2015 (Fig. 2) also shows a significant upward trend, which is consistent with the above analysis conclusion.

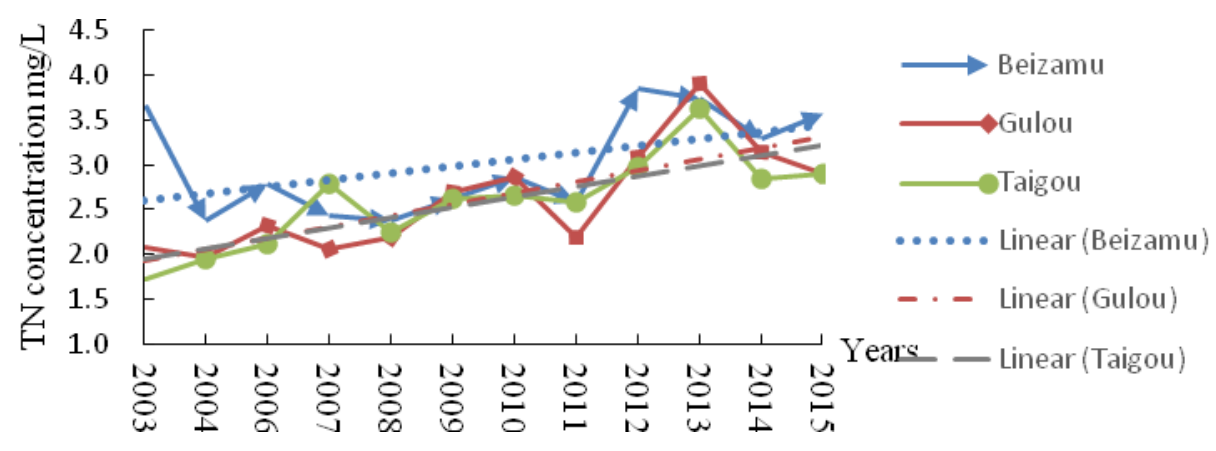

Figure 2. Interannual variation curves and linear analysis of total nitrogen concentration in three sections from 2003 to 2015

\section{Conclusions}

Based on the monitoring data of water quality in the upstream of Dahuofang Reservoir from 2003 to 2015 and according to the NSWQ, the water quality evaluation and water quality variation trend analysis were carried out to Hunhe River, Suzihe River and Shehe River, the three major rivers upstream of Dahuofang Reservoir. The Nemerow index method was used to preliminarily evaluate the river water quality at the three sections of Beizamu, Gulou and Taigou. 8 indicators of each section, totaling 24 indicators, were compared with the pollution grade classification standard of Nemerow water quality index. Among the original 24 pollution indicators, according to the evaluation results, the clean indicators were eliminated, the pollution indicators of different degrees were retained, and the indicators were reduced from 24 to 8 . Then seasonal Kendall test method was applied to test the 8 indicators, and to predict the variation trend of water quality.

The results show that the order of water quality of the three sections is: Taigou section > Gulou section > Beizamu section. The TN concentrations in the three sections 
belong to serious pollution and have a highly significant upward trend. The fecal coliform floras of the three sections are polluted to varying degrees, and the pollution in Beizamu section is the most serious. Therefore, the application of pesticides and fertilizers should be reduced as far as possible, non-point source pollution should be controlled, and eutrophication of water body should be prevented. At the same time, effective measures must be taken to ensure that domestic sewage treatment meets the discharge standards.

\section{REFERENCES}

[1] Dahuofang Reservoir Chronicles (2006): The Authority of Dahuofang Reservoir in Liaoning Province. - China Water \& Power Press, Beijing.

[2] Fang, X. (2017): Research on water quality change trend based on seasonal Kendall testing method. - Heilongjiang Water Resources 3(2): 55-58.

[3] Gao, W., Chen, Y., Xu, M. (2013): Trend and driving factors of water quality change in lake Fuxian (1980-2011). - Journal of Lake Sciences 25(5): 635-642.

[4] Guan, X. J., Liu, W. K., Hu, D. (2017): Application of CRITIC-based pollution index in water quality assessment of Qingyi River. - Water Resources and Power 35(8): 49-52.

[5] Guo, X. S. (2017): Analysis of water quality trend of Zhanwu South China Sea reservoir from 2010 to 2016. - Haihe River Water Conservancy 4: 17-19.

[6] Huang, R., Han, L. X., Zhang, H. (2013): Water quality evaluation of Dahuofang Reservoir based on fuzzy evaluation and AHP method. - Yellow River 35(4): 32-34.

[7] Kendall, M. G. (1975): Rank Correlation Methods. 4th Ed. - Charles Griffin, London.

[8] Liu, C. H., Xu, L. G., Gao, H. Y. (2010): River water quality assessment methods and their research progress. - Journal of Hohai University 38(2): 290-293.

[9] Liu, L. H., Wu, L. X., Wu, J. P. (2016): Review on surface water quality index assessment method in foreign countries. - Water Resources Protection 32(1): 86-90.

[10] Luo, F., Wu, G. R., Wang, C. (2016): Application of Nemerow Pollution Index Method and single-factor evaluation method in water quality evaluation. - Environment and Sustainable development 5: 87-89.

[11] Luo, X. Q., Zhang, Q., Chen, L. Y., Meng, Q. X. (2016): Comprehensive water quality assessment of upper Nanminghe River in Guiyang based on single-factor index method. Groundwater 38(1): 80-82.

[12] Ma, L. L., Zhou, L. F., Wang, T. L. (2014): Water quality evaluation of Dahuofang Reservoir based on BP neural network. - Journal of Shenyang Agricultural University 45(5): 637-640.

[13] Mann, H. B.(1945): Nonparametric tests against trend. - Econometrica 13(3): 245-259.

[14] Meng, C. X., Wang, X. B., Huang, Y.(2015): Analysis of water quality tendency of the mainstream of Minjiang river with Seasonal Kendall Method. - Sichuan Environment 34(06): 87-93.

[15] Ministry of Environmental Protection (2002): Environmental Quality Standards for Surface Water, GB3838-2002, P.R.C. - China Environmental Science Press, Beijing.

[16] Ministry of Water Resources of the People's Republic of China (2017): China Water Resources Bulletin. - Ministry of Water Resources Information Center, Beijing.

[17] Onoz, B., Bayazit, M. (2003): The power of statistical tests for trend detection. - Turkish Journal of Engineering and Environmental Sciences 27: 247-251.

[18] Pan, F., Fu, Q., Liang, C. (2002): Application research of fuzzy comprehensive evaluation in comprehensive evaluation of water environment quality. - Environmental Engineering 20(2): 58-61.

[19] Pang, Y., Zhang, M. Z., Pang, Z. Y. (2017): Analysis and evaluation of groundwater quality in Guanghua basin. - Water Resources and Power 35(11): 40-43+35. 
[20] Ren, J. L., Jing, H. L. (2011): Analysis and evaluation of water quality of Aibihu Lake Wetland Nature Reserve. - Journal of Arid land resources and Environment 25(5): 154157.

[21] Robert, M. H., Slack, J. R. (1984): A nonparametric trend test for seasonal date with serial dependence. - Water Resources Research 20(6): 727-732.

[22] Shi, Y. Q., Sun, X. Y. (2004): Study on Water Quality Ecology of Dahuofang Reservoir in Liaoning Province. - Chinese Society of Environmental Sciences, Shenyang.

[23] Tang, X. N. (2016): Analysis on the Source of Water Pollution in the Upper River of Dahuofang Reservoir. - Beijing University of Science and Technology, Beijing.

[24] Yin, H. L., Xu, Z. X. (2008): Comparative study of river water quality assessment methods. - Resources and Environment in the Yangtze Basin 17(5): 729-733.

[25] Yuan, D., Fu, D. Y. (2003): Application of cluster analysis to water environment quality assessment. - Journal of Sichuan Institute of Light Industry and Chemical Technology 16(3): $50-55$.

[26] Zhou, Y. C., Li, H. (2015): Application of grey clustering method based on index transformation value in water quality evaluation. - Gansu Water Resources and Hydropower Technology 1: 6-8. 